\title{
Effect of antifibrotic agents on survival in idiopathic pulmonary fibrosis patients according to forced vital capacity: a real-world retrospective cohort study in Japan
}

\section{Sho Saeki}

Kindai University Faculty of Medicine

Osamu Nishiyama ( $\square$ nishiyama_o@yahoo.co.jp)

Kindai University Faculty of Medicine https://orcid.org/0000-0002-9163-9605

Ryo Yamazaki

Kindai University Faculty of Medicine

Kazuya Yoshikawa

Kindai University Faculty of Medicine

Ken Shirahase

Kindai University Faculty of Medicine

Kyuya Gose

Kindai University Faculty of Medicine

Takashi Oomori

Kindai University Faculty of Medicine

\section{Yusaku Nishikawa}

Kindai University Faculty of Medicine

\section{Akiko Sano}

Kindai University Faculty of Medicine

Hiroyuki Sano

Kindai University Faculty of Medicine

Takashi Iwanaga

Kindai University Faculty of Medicine

Yuji Tohda

Kindai University Faculty of Medicine

\section{Research article}

Keywords: forced vital capacity, idiopathic pulmonary fibrosis, nintedanib, pirfenidone, survival

Posted Date: June 12th, 2020 
DOI: https://doi.org/10.21203/rs.3.rs-34466/v1

License: (c) (1) This work is licensed under a Creative Commons Attribution 4.0 International License. Read Full License 


\section{Abstract \\ Background}

Antifibrotic agents suppress the decline in forced vital capacity (FVC) and disease progression in idiopathic pulmonary fibrosis (IPF) patients. However, their effect on survival prognosis and differences in this effect according to baseline lung function have been unexplored. Therefore, this study aimed to examine the effect of antifibrotics on survival prognosis and whether this effect differed according to baseline FVC.

\section{Methods}

Consecutive IPF patients from January 2008 to May 2019 were examined retrospectively. FVC and effect of pirfenidone or nintedanib therapy were assessed. FVC at registration was used to categorize the patients into mild: FVC $\%$ predicted $\geq 80 \%$, moderate: FVC $\%$ predicted $50-80 \%$, and severe: FVC $\%$ predicted $<50 \%$ IPF groups.

\section{Results}

In total, 172 IPF patients were included. The mean FVC \% predicted was $77.4 \pm 22.2 \%$. The median survival periods of patients in the mild, moderate, and severe IPF groups were 1,452, 1,305, and 481 days, respectively. Significant differences were observed in survival between the mild and severe groups and the moderate and severe groups $(p<0.0001)$, but not between the mild and moderate groups $(p=0.20)$. The survival was longer in patients on antifibrotic therapy in the mild $(p=0.18)$ and moderate groups $(p=$ $0.04)$, but not in the severe group $(p=0.93)$.

\section{Conclusions}

Antifibrotics extended the survival of IPF patients. The effect was obvious in patients with FVC \% predicted of $50-80 \%$, a tendency was observed in patients with FVC \% predicted $\geq 80 \%$, while no effect was observed in patients with FVC \% predicted $<50 \%$.

\section{Introduction}

Idiopathic pulmonary fibrosis (IPF) is a progressive, refractory condition, and the most common form of idiopathic interstitial pneumonia [1, 2]. The fibrosis progresses slowly, leading to respiratory dysfunction and eventually, death [3].

Two antifibrotic agents, which suppress the decline in forced vital capacity (FVC) over time, are currently available for the management of IPF-pirfenidone and nintedanib [4, 5]. In addition, nintedanib can delay 
the time to acute exacerbation [5]. Recently, retrospective cohort studies performed in several countries have found that patients with IPF on oral antifibrotic therapy survive longer [6-8].

Antifibrotics have not been shown to extend the survival of IPF patients in Japan or Asia, and no reports have analyzed the effect of baseline lung function on prognosis. Hence, we conducted a retrospective cohort study with IPF patients to examine the effect of antifibrotics on survival prognosis and whether this effect differed according to baseline FVC.

\section{Methods}

\section{Patients}

Consecutive IPF patients who visited our outpatient department at the Kindai University Hospital from January 2008 to May 2019 were examined retrospectively. The date of first pulmonary function test during this period was used as the registration date. Patients with a history of malignancy at registration or who were diagnosed with IPF before 3 or more years were excluded. IPF was diagnosed based on the ATS/ERS/JRS/ALAT clinical practice guideline [9].

\section{Clinical evaluation}

A pulmonary function test such as FVC and diffusion capacity by the single-breath method were measured (CHESTAC-8800, Chest, Tokyo, Japan). All measurements were performed according to the method proposed by the European Respiratory Society $[10,11]$. The ratio of estimated lung function to the predicted value was expressed in \% using a Japanese prediction formula $[12,13]$.

We surveyed whether the patients were prescribed pirfenidone or nintedanib, the antifibrotic agents analyzed in this study, during the observation period. A patient was considered to have undergone antifibrotic therapy if an antifibrotic was prescribed for at least 6 months during the observation period.

Assessment of survival

Survival was assessed up to May 31, 2019. The number of deaths was determined retrospectively by examining the medical records. Patients who had moved or did not continue the treatment were investigated by calling the patient or family members. The survival period was defined from the date of registration to the date of death. For patients who could not be tracked, the survival period was defined from the date of registration to the last date when they were confirmed to be alive; they were treated as censored cases. The cause of death was determined by the in-charge physician and was mentioned in the medical records. The cause of death was regarded as unknown in patients who had died but their medical records could not be examined.

Statistical analysis 
Continuous variables were expressed as mean \pm standard deviation, and categorical variables as the actual number. The t-test was used for comparisons between two groups. The analysis of variance was used for comparisons among three groups, and Bonferroni analysis was used for intergroup comparisons. FVC at registration was used to categorize the patients into mild: FVC \% predicted $\geq 80 \%$, moderate: FVC \% predicted $<80 \%$ and $\geq 50 \%$, and severe: FVC $\%$ predicted $<50 \%$ IPF groups. The log-rank test using Kaplan-Meyer survival curves was used to compare the prognosis. $\mathrm{P}<0.05$ was considered statistically significant. The StatFlex ver. 6 software (Artec Inc. Osaka, Japan) was used for statistical analysis.

\section{Results}

One hundred and seventy-three IPF patients were reported during the registration period, of which one patient with cancer at registration was excluded. Finally, 172 patients were included in the statistical analysis. Table 1 shows the patients' characteristics. Their mean age was $73.9 \pm 6.4$ years, and 137 were men (79.6\%). Regarding smoking history, 18 patients were current smokers, 99 were former smokers, 21 never smokers, and in 35 patients, the history was unknown. The mean FVC \% predicted and diffusion capacity of carbon monoxide (DLCo) \% predicted were $77.4 \pm 22.2 \%$ and $71.1 \pm 22.4 \%$, respectively. Table 2 shows the characteristics of the mild, moderate, and severe IPF groups.

Table 1

Patient characteristics

\begin{tabular}{|ll|}
\hline Age, years & $73.9 \pm 6.4$ \\
\hline Gender, male/female & $137 / 35$ \\
\hline Smoking status, current/former/never & $18 / 99 / 20$ \\
\hline Height, cm & $160.1 \pm 8.1$ \\
\hline Weight, $\mathrm{kg}$ & $57.9 \pm 10.7$ \\
\hline FVC, L & $2.5 \pm 0.8$ \\
\hline$\% \mathrm{FVC}, \%$ & $77.4 \pm 22.2$ \\
\hline DLco, $\mathrm{mL} / \mathrm{min} / \mathrm{mmHg}$ & $10.4 \pm 3.7$ \\
\hline$\% \mathrm{DLco} \%$ & $71.1 \pm 22.4$ \\
\hline Antifibrotic therapy, yes/no & $42 / 130$ \\
\hline $\mathrm{N}=172$ & \\
\hline Data are shown as mean \pm standard deviation or the actual number. \\
\hline Smoking status was unknown in 35 patients. \\
\hline DLco, diffusing capacity for carbon monoxide; FVC, forced vital capacity \\
\hline
\end{tabular}


Table 2

Characteristics of patients in the mild, moderate, and severe idiopathic pulmonary fibrosis groups.

\begin{tabular}{|c|c|c|c|c|}
\hline & Mild & Moderate & Severe & \multirow[t]{2}{*}{$P$} \\
\hline & $N=77$ & $N=77$ & $N=18$ & \\
\hline Age, years & $73.2 \pm 6.4$ & $74.8 \pm 6.5$ & $73.3 \pm 6.2$ & 0.27 \\
\hline Gender, male/female & $72 / 5$ & $52 / 25$ & $13 / 5$ & $<0.0001$ \\
\hline \multicolumn{5}{|l|}{ current/former/never } \\
\hline Height, cm & $162.6 \pm 7.3$ & $158.3 \pm 8.3^{*}$ & $157.9 \pm 8.5$ & 0.001 \\
\hline Weight, kg & $60.6 \pm 9.2$ & $56.4 \pm 10.3^{*}$ & $52.9 \pm 14.9 *$ & 0.004 \\
\hline FVC, L & $3.2 \pm 0.6$ & $2.1 \pm 0.4^{*}$ & $1.23 \pm 0.23^{*^{\dagger}}$ & $<0.0001$ \\
\hline$\% F V C, \%$ & $96.4 \pm 15.5$ & $67.2 \pm 8.0^{\star}$ & $40.1 \pm 6.8^{*^{\dagger}}$ & $<0.0001$ \\
\hline $\mathrm{DLco}, \mathrm{mL} / \mathrm{min} / \mathrm{mmHg}$ & $11.3 \pm 3.2$ & $9.6 \pm 3.6^{*}$ & $8.46 \pm 2.56$ & 0.02 \\
\hline$\% D L c o, \%$ & $75.8 \pm 22.5$ & $67.3 \pm 21.4$ & $44.1 \pm 9.4^{\star}$ & 0.01 \\
\hline Antifibrotic therapy, yes/no & $17 / 60$ & $21 / 56$ & $4 / 14$ & 0.83 \\
\hline \multicolumn{5}{|c|}{$N=70,70$, and 3 for DLco and \%DLco in the mild, moderate, and severe groups, respectively } \\
\hline \multicolumn{5}{|c|}{ Data are shown as mean \pm standard deviation or the actual number. } \\
\hline \multicolumn{5}{|c|}{ Smoking status was unknown in 35 patients. } \\
\hline \multicolumn{5}{|c|}{ *, significantly different to the mild group; + , significantly different to the moderate group } \\
\hline \multicolumn{5}{|c|}{ DLco, diffusing capacity for carbon monoxide; FVC, forced vital capacity } \\
\hline
\end{tabular}

The mean observation period was 1,114 \pm 790 days. The median survival period of the 172 patients was 1,349 days. The median survival periods of patients in the mild, moderate, and severe IPF groups were $1,452,1,305$, and 481 days, respectively. Figure 1 shows the survival curves of each group. A significant difference was observed among the 3 groups (log-rank: $p<0.001)$. When comparing the survival between 2 groups, significant differences were observed between the mild and severe groups and between the moderate and severe groups (log-rank: $p<0.0001)$, but not between the mild and moderate groups (logrank: $p=0.20)$.

One hundred and two deaths occurred during the observation period (mild, 40; moderate, 46; and severe, 16). Table 3 summarizes the causes of death. While the causes were unknown in several patients, those that could be identified included acute exacerbation of IPF, chronic respiratory failure, pneumonia, lung cancer, other cancers, cardiovascular disease, cerebrovascular disease, sepsis, chronic kidney disease, 
and pulmonary hypertension. Of these, a significant difference in the mortality rate due to lung cancer was observed among the 3 groups $(p=0.02)$.

Table 3

Causes of death.

\begin{tabular}{|lllll|}
\hline & Mild & Moderate & Severe & $P$ \\
\hline Acute exacerbation & $\mathbf{N}=\mathbf{4 0}$ & $\mathbf{N = 4 6}$ & $\mathbf{N = 1 6}$ & \\
\hline Respiratory failure & $4(10.0)$ & $10(21.7)$ & $3(18.7)$ & 0.45 \\
\hline Pneumonia & $2(5.0)$ & $6(13.0)$ & $1(6.2)$ & 0.45 \\
\hline Lung cancer & $3(7.5)$ & $6(13.0)$ & $6(37.5)$ & 0.06 \\
\hline Cancer other than lung cancer ${ }^{\dagger}$ & $9(22.5)^{*}$ & $2(4.3)$ & $0(0)$ & 0.02 \\
\hline Cerebrovascular disease & $4(10.0)$ & $2(4.3)$ & $0(0)$ & 0.33 \\
\hline Myocardial infarction & $1(2.5)$ & $1(2.1)$ & $0(0)$ & 0.82 \\
\hline Sepsis & $0(0)$ & $0(0)$ & $1(6.2)$ & 0.07 \\
\hline Chronic kidney disease & $0(0)$ & $1(2.1)$ & $0(0)$ & 0.54 \\
\hline Pulmonary hypertension & $0(0)$ & $1(2.1)$ & $0(0)$ & 0.54 \\
\hline Unknown & $0(0)$ & $0(0)$ & $1(6.2)$ & 0.07 \\
\hline Data are shown as actual number and \% in parenthesis. & & $4(25.0)$ & 0.68 \\
\hline *significantly different to the moderate group & $17(42.5)$ & $17(36.9)$ & \\
\hline $\begin{array}{l}\text { †, 1 gastric, 1 colorectal, 1 pharyngeal, and 1 liver cancer in the mild group and 1 pancreatic and 1 } \\
\text { esophageal cancer in the moderate group. }\end{array}$ & & & \\
\hline
\end{tabular}

During the observation period, antifibrotics were administered to 17 (42.5\%), 21 (45.6\%), and 4 (25.0\%) patients in the mild, moderate, and severe IPF groups, respectively. Overall, patients on antifibrotic therapy showed significantly longer survival than patients who were not $(p=0.02)$ (Fig. 2$)$. Figure 3 shows the survival curves for the mild, moderate, and severe IPF groups based on the use of antifibrotics. Although the difference was not statistically significant in the mild group, survival tended to be longer in patients on antifibrotic therapy $(p=0.18)$. In the moderate group, survival was significantly longer in patients on antifibrotic therapy $(p=0.04)$. In the severe group, survival did not differ significantly with antifibrotic therapy $(p=0.93)$.

\section{Discussion}


In this study, we examined the survival prognoses of IPF patients in actual clinical practice and compared the survival prognoses depending on the use of antifibrotics. Patients with IPF were categorized by FVC \% predicted into mild: FVC \% predicted $\geq 80 \%$, moderate: FVC $\%$ predicted $<80 \%$ and $\geq 50 \%$, and severe: FVC $\%$ predicted $>50 \%$ groups, which exhibited significantly different survival periods. Significant differences in survival periods were observed between the mild and severe groups and between the moderate and severe groups, but not between the mild and moderate groups. Further, survival was significantly longer in patients on antifibrotic therapy. This effect was most obvious in the moderate group and a tendency was observed in the mild group, with no effect in the severe group.

Although survival was longest in patients in the mild group, the median survival was approximately 4 years, showing that the survival prognosis may not necessarily be good even in patients with FVC \% predicted $\geq 80 \%$ and mild respiratory problems. Several other studies have compared survival by stratifying FVC. The Australian IPF Registry (AIPFR) compared the prognosis between FVC \% predicted $\geq$ $80 \%$ and $<80 \%$ groups, showing significantly longer survival in the FVC $\%$ predicted $\geq 80 \%$ group [14]. In addition, a Japanese study stratified vital capacity (VC) \% predicted in $>80 \%, 60-80 \%, 40-60 \%$, and < $40 \%$ groups, and found significantly better prognosis in the VC \% predicted $>80 \%$ group [15]. However, in this study, the median survival of the FVC \% predicted $\geq 80 \%$ (mild) group was approximately 4 years, which is shorter than 4.5 years or more in the AIPFR and 4.8 years in the Japanese study. One reason for this could be the significant number of deaths due to lung cancer in the mild group. Nine of 40 deaths $(22.5 \%)$ in the mild group occurred due to lung cancer, significantly more than those in the moderate and severe groups. The two studies mentioned above did not report the number of deaths due to lung cancer, though mortality rate due to lung cancer in the SEPAR National Registry was reported as $9.1 \%[16]$ and in a Hokkaido study as approximately $11 \%$ [17]. Despite the considerable number of deaths due to unknown causes in our study, deaths due to lung cancer constituted a significant proportion of deaths in the mild group (22.5\%), which probably could have affected the survival prognosis. If the cause of death in the unknown cases could be determined, the number of deaths due to lung cancer may be even higher. It is unclear why the mild group exhibited pronounced number of deaths due to lung cancer, though it may be associated with the high percentage of men in this group.

Our results showed that administration of antifibrotics significantly extended the survival of IPF patients. Several reports have indicated that antifibrotics can extend the survival of IPF patients. The European IPF registry and AIPFR showed significantly longer survival in patients treated with antifibrotics $[14,18]$. For specific a drug, the EMPIRE registry showed that patients treated with pirfenidone exhibited significantly longer survival [19]. In a joint analysis of the phase 2 and 3 trials of nintedanib, the treatment group showed a significantly lower mortality rate than the placebo group [18]. In addition, long-term observations have also revealed longer survival periods for patients on antifibrotic therapy [20]. Compared to these reports, relatively shorter survivals were observed in patients of our study. One reason could be the high mean age of 74 years in our patients. The mean ages of patients in the EMPIRE registry was 67 years [19], in the European IPF registry was 68 years [18], and in the AIPFR was 70.9 years [14]. However, to the best of our knowledge, this is the first study from Japan and Asia. 
Antifibrotics showed a statistically significant effect in the moderate group only. An FVC of $50-80 \%$ is consistent with the range suggested as the eligibility criteria for several clinical trials [21], and also with the National Institute for Health and Care Excellence guidance on the indications of antifibrotic agents $[22,23]$. Antifibrotic therapy has been shown to be useful for extending the prognosis in patients with $50-$ $80 \% \mathrm{FVC}$, which is the most commonly used FVC value for studying the efficacy of antifibrotic therapy. In contrast, antifibrotics did not significantly extend the survival in the mild group. A comparison of the survival curves showed that in the group not treated with antifibrotics, the survival was longer in the mild group than that in the moderate group, which could mean that antifibrotics are less likely to show positive effects for patients in the mild group. However, survival of the group on antifibrotic therapy was clearly longer than the group not on antifibrotic therapy, which suggests that antifibrotics do show an effect. It is possible that a statistically significant difference would have been observed if more cases had been examined. It is interesting that antifibrotics did not show an effect in the severe group. Although the sample size was small, the survival curves almost completely overlapped and only few censored cases were evident, suggesting that the findings are true. As the survival duration of patients in this group was short, the duration of antifibrotic therapy was also short, which could account for the absence of any effect. Moreover, advanced cases are more likely to experience side-effects and suspend the antifibrotic therapy, which may have further shortened the duration of treatment [24]. Nonetheless, it can be safely concluded that effective treatment modalities for severe IPF cases with FVC \% predicted $<50 \%$ should be developed.

This study had several limitations. First, it was a retrospective study, resulting in a considerable proportion of missing data, such as that on DLco. Second, the observations were censored in many cases due to transfer in different hospitals and/or patients shifting to a different location. In many patients, the cause of death could not be identified. Third, the severe group had a small sample size. While the results of survival analysis for the severe group may have been different if more cases were included, only few censored cases were evident in this group, which indicates that the results are accurate. Finally, antifibrotic therapy was defined as treatment with antifibrotic drugs for at least 6 months, and since we did not consider the commencing time of antifibrotic therapy, some lead time bias is possible. Nonetheless, previous studies have also used a duration of 6 months or more to define antifibrotic therapy, which indicates that our definition is valid [25]. A prospective observational study should be conducted to validate the results of this study. One advantage of this study is that it used data from actual clinical practice and included severe IPF cases with FVC \% predicted $<50 \%$, which means it reflected real-world conditions. Severe IPF patients with FVC $\%$ predicted $<50 \%$ are usually excluded from large phase 3 trials, which does not reflect the real-world conditions.

The results of this study showed that the survival prognosis of IPF patients was poor even in the group with maintained pulmonary function at FVC \% predicted $\geq 80 \%$. Even early-stage IPF patients show rapid disease progression and unfavorable prognoses [26,27], which is similar to the results of our study. Our study showed that antifibrotics may show a positive effect on survival even in patients with FVC \% predicted $\geq 80 \%$. This indicates that antifibrotic therapy should be considered even for early-stage cases. In the moderate IPF group with FVC \% predicted of $50-80 \%$, which showed a poorer prognosis, 
antifibrotics showed a significantly positive effect on survival, indicating that treatment with antifibrotics is more important for these patients. In contrast, in the severe IPF group with FVC \% predicted $<50 \%$, antifibrotics may show a limited effect on survival. Therefore, early antifibrotic therapy before FVC \% predicted drops below $50 \%$ is the best treatment protocol. However, each individual case should be considered carefully to determine the most appropriate treatment modality.

Our results showed through a real-world analysis that antifibrotics extended the survival of IPF patients. The effect was obvious in the moderate IPF group with FVC \% predicted of $50-80 \%$. A tendency was observed in the mild IPF group with FVC $\%$ predicted $\geq 80 \%$, while no effect on survival was observed for the severe IPF group with FVC \% predicted $<50 \%$.

\section{Declarations}

\section{Ethics approval and consent to participate}

The ethics committee of the Faculty of Medicine at Kindai University approved the use and analysis of this data (No. 31-072). The need for informed consent was waived due to the retrospective nature of the study.

\section{Availability of data and materials}

The datasets used and/or analysed during the current study are available from the corresponding author on reasonable request.

\section{Competing interests}

YT received funding out of this work from Nippon Boehringer Ingelheim, Co., Ltd.. ON, and TY received lecture fee from Nippon Boehringer Ingelheim, Co., Ltd. and SHIONGI \& CO. LTD.. HS and TI received lecture fee from Boehringer Ingelheim, Co., Ltd. SS, RY, KY, KS, KG, YN, and AS have no competing interest to declare in relation to this work.

\section{Funding}

There was no funding to support this work.

\section{Authors' contributions}

Manuscript conception and design: O.N.; data collection and data analysis: S.S., O.N., R.Y., K.Y., K.S., K.G., T.O., Y.N., A.S.; data interpretation: S.S., O.N.; project administration: Y.T.; writing the draft of manuscript: S.S.; critical revision and editing the final manuscript: O.N., H.S., T.I.; Guarantors of this manuscript: Y.T.

\section{References}


1. American Thoracic Society, European Respiratory Society. American Thoracic Society/European Respiratory Society Statement on Pulmonary Rehabilitation. Am J Respir Crit Care Med. 2002;165:277-304.

2. Raghu G, Collard HR, Egan JJ, Martinez FJ, Behr J, Brown KK, et al. An official ATS/ERS/JRS/ALAT statement: idiopathic pulmonary fibrosis: evidence-based guidelines for diagnosis and management. Am J Respir Crit Care Med. 2011;183:788-824.

3. Lederer DJ, Martinez FJ. Idiopathic Pulmonary Fibrosis. N Engl J Med. 2018;378:1811-23.

4. King TE Jr, Bradford WZ, Castro-Bernardini S, Fagan EA, Glaspole I, Glassberg MK, et al. for the ASCEND Study Group. A phase 3 trial of pirfenidone in patients with idiopathic pulmonary fibrosis. $\mathrm{N}$ Engl J Med. 2014;370:2083-92.

5. Richeldi L, du Bois RM, Raghu G, Azuma A, Brown KK, Costabel U, et al. Efficacy and safety of nintedanib in idiopathic pulmonary fibrosis. N Engl J Med. 2014;370:2071-82.

6. Dempsey TM, Sangaralingham LR, Yao X, Sanghavi D, Shah ND, Limper AH. Clinical Effectiveness of Antifibrotic Medications for Idiopathic Pulmonary Fibrosis. Am J Respir Crit Care Med. 2019;200:168-74.

7. Jo HE, Glaspole I, Grainge C, Goh N, Hopkins PM, Moodley Y, et al. Baseline characteristics of idiopathic pulmonary fibrosis: analysis from the Australian Idiopathic Pulmonary Fibrosis Registry. Eur Respir J. 2017;49:1601592.

8. Guenther A, Krauss E, Tello S, Wagner J, Paul B, Kuhn S, et al. The European IPF registry (eurlPFreg): baseline characteristics and survival of patients with idiopathic pulmonary fibrosis. Respir Res. 2018;19:141.

9. Raghu G, Remy-Jardin M, Myers JL, Richeldi L, Ryerson CJ, Lederer DJ, et al. Diagnosis of Idiopathic Pulmonary Fibrosis. An Official ATS/ERS/JRS/ALAT Clinical Practice Guideline. Am J Respir Crit Care Med. 2018;198:e44-68.

10. Miller MR, Hankinson J, Brusasco V, Burgos F, Casaburi R, Coates A, et al. Standardisation of spirometry. Eur Respir J. 2005;26:319-38.

11. Macintyre N, Crapo RO, Viegi G, Johnson DC, van der Grinten CP, Brusasco V, et al. Standardisation of the single-breath determination of carbon monoxide uptake in the lung. Eur Respir J. 2005;26:72035.

12. Kubota M, Kobayashi H, Quanjer PH, Omori H, Tatsumi K, Kanazawa M. Reference values for spirometry, including vital capacity, in Japanese adults calculated with the LMS method and compared with previous values. Respir Investig. 2014;52:242-50.

13. Sasaki H, Nakamura M, Kida K, Kambe M, Takahashi K, Fujimura M, et al. Reference values for spirometry and pressure of arterial oxygen in Japanese adults J. Jpn Respir Soc. 2001;39:1-17.

14. Jo HE, Glaspole I, Moodley Y, Chapman S, Ellis S, Goh N, et al. Disease progression in idiopathic pulmonary fibrosis with mild physiological impairment: analysis from the Australian IPF registry. BMC Pulm Med. 2018;18:19. 
15. Homma S, Sugino K, Sakamoto S. The usefulness of a disease severity staging classification system for IPF in Japan: 20 years of experience from empirical evidence to randomized control trial enrollment. Respir Investig. 2015;53:7-12.

16. Fernández-Fabrellas E, Molina-Molina M, Soriano JB, Portal JAR, Ancochea J, Valenzuela C, et al. Demographic and clinical profile of idiopathic pulmonary fibrosis patients in Spain: the SEPAR National Registry. Respir Res. 2019;20:127.

17. Natsuizaka M, Chiba H, Kuronuma K, Otsuka M, Kudo K, Mori M, et al. Epidemiologic survey of Japanese patients with idiopathic pulmonary fibrosis and investigation of ethnic differences. Am J Respir Crit Care Med. 2014;190(7):773-9.

18. Richeldi L, Cottin V, du Bois RM, Selman M, Kimura T, Bailes Z, et al. Nintedanib in patients with idiopathic pulmonary fibrosis: Combined evidence from the TOMORROW and INPULSIS ${ }^{\circledR}$ trials. Respir Med. 2016;113:74-9.

19. Zurkova M, Kriegova E, Kolek V, Lostakova V, Sterclova M, Bartos V, et al. Effect of pirfenidone on lung function decline and survival: 5-yr experience from a real-life IPF cohort from the Czech EMPIRE registry. Respir Res. 2019;20:16.

20. Lancaster L, Crestani B, Hernandez P, Inoue Y, Wachtlin D, Loaiza L,et al. Safety and survival data in patients with idiopathic pulmonary fibrosis treated with nintedanib: pooled data from six clinical trials. BMJ Open Respir Res. 2019;6:e000397.

21. Taniguchi H, Ebina M, Kondoh Y, Ogura T, Azuma A, Suga M, et al. Pirfenidone in idiopathic pulmonary fibrosis. Eur Respir J. 2010;35:821-29.

22. Landells LJ, Naidoo B, Robertson J, Clark P. NICE guidance on pirfenidone for treating idiopathic pulmonary fibrosis. Lancet Respir Med. 2013;1:191-2.

23. Laurenson S, Sidhu R, Goodall M, Adler AI. NICE guidance on nintedanib for treating idiopathic pulmonary fibrosis. Lancet Respir Med. 2016;4:176-7.

24. Oishi K, Hirano T, Murata Y, Hamada K, Uehara S, Suetake R, et al. Medication persistence rates and predictive factors for discontinuation of antifibrotic agents in patients with idiopathic pulmonary fibrosis: a real-world observational study. Ther Adv Respir Dis. 2019;13:1-15.

25. Dempsey TM, Sangaralingham LR, Yao X, Sanghavi D, Shah ND, Limper AH. Clinical Effectiveness of Antifibrotic Medications for Idiopathic Pulmonary Fibrosis. Am J Respir Crit Care Med. 2019;200:168-74.

26. Yamauchi H, Bando M, Baba T, Kataoka K, Yamada Y, Yamamoto H, et al. Clinical Course and Changes in High-Resolution Computed Tomography Findings in Patients with Idiopathic Pulmonary Fibrosis without Honeycombing. PLoS One. 2016;11:e0166168.

27. Kondoh Y, Taniguchi H, Ogura T, Johkoh T, Fujimoto K, Sumikawa H, et al. Disease progression in idiopathic pulmonary fibrosis without pulmonary function impairment. Respirology. 2013;18:820-26.

\section{Figures}




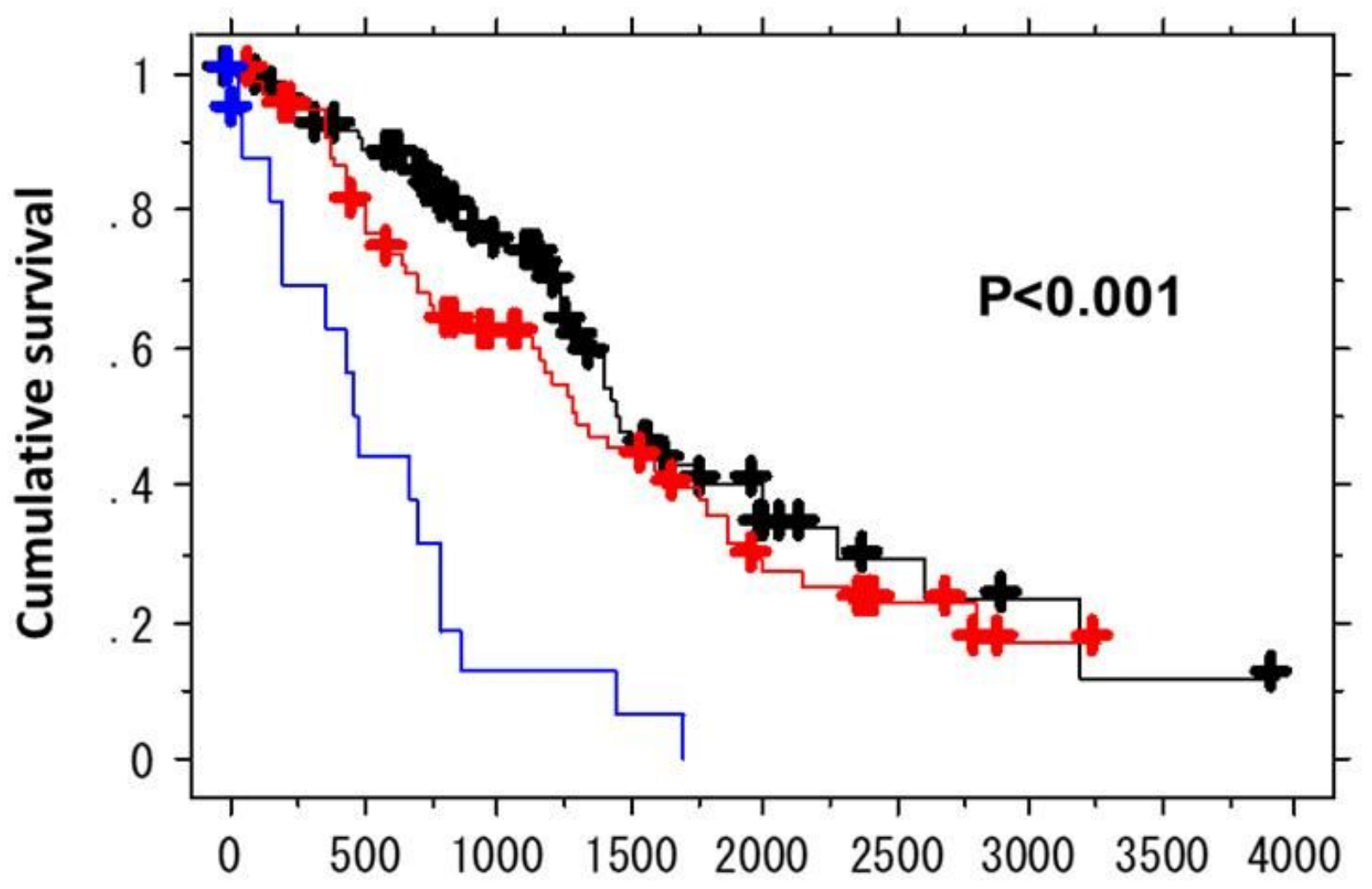

Days

Figure 1

Survival curves by severity based on forced vital capacity (FVC). Black: mild (FVC $\%$ predicted $\geq 80 \%$ ), Red: moderate (FVC \% predicted $<80 \%$ and $\geq 50 \%$ ), Blue: severe (FVC \% predicted $<50 \%$ ) + Censored 


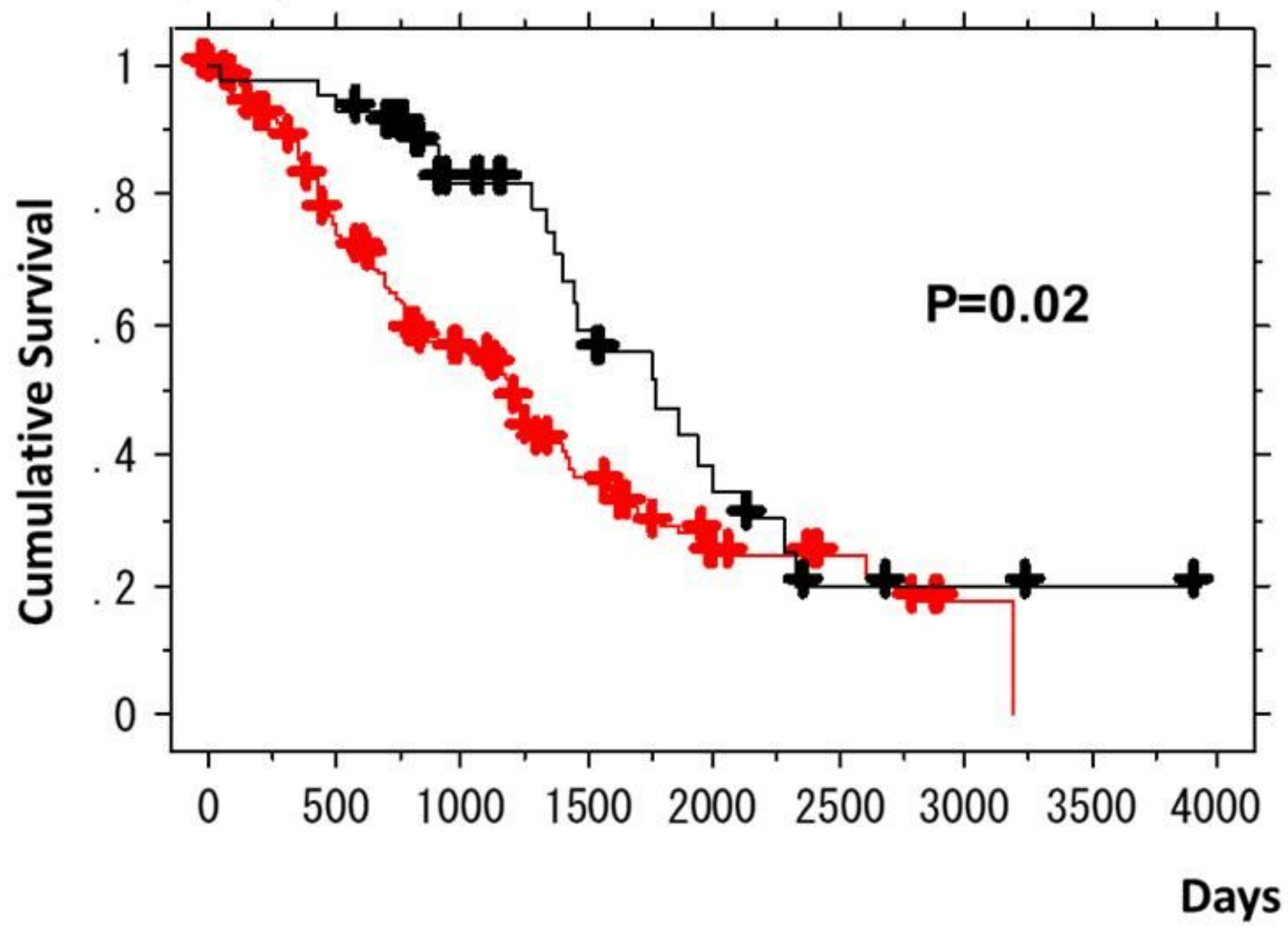

Figure 2

Survival curves with and without antifibrotic therapy. Black: with antifibrotic therapy, Red: no antifibrotic therapy + Censored 

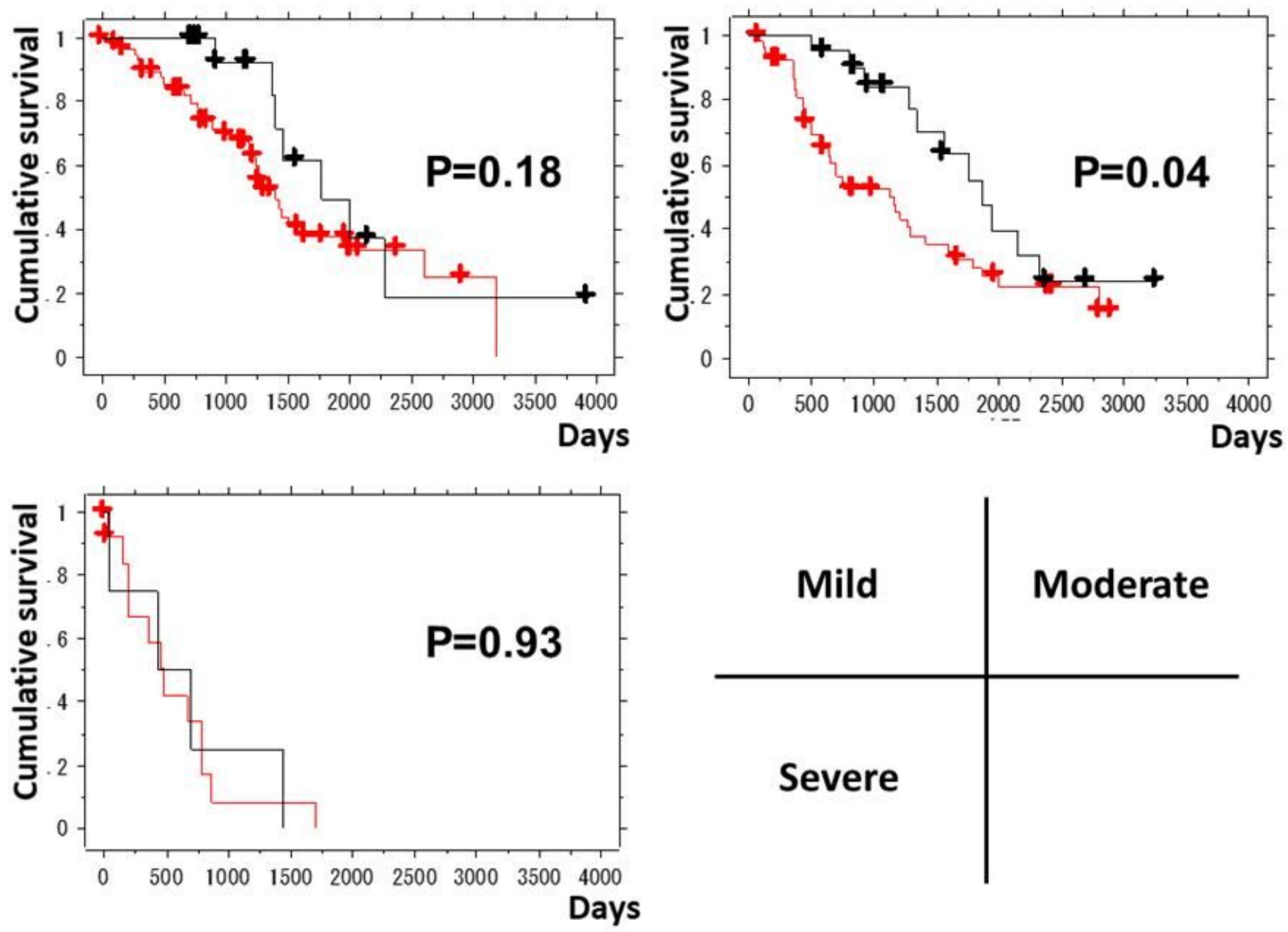

Figure 3

Survival curves with and without antifibrotic therapy by severity based on forced vital capacity. Black: with antifibrotic therapy, Red: no antifibrotic therapy, Mild: FVC \% predicted $\geq 80 \%$, Moderate: FVC $\%$ predicted $<80 \%$ and $\geq 50 \%$, Severe: FVC $\%$ predicted $<50 \%+$ Censored 